\title{
Evaluación del riesgo inmunológico
}

\author{
Immunological Risk Assessment \\ Luis Eduardo Morales-Buenrostro* \\ * Área de Nefrología del Trasplante, Departamento de Nefrología y Metabolismo Mineral. \\ Instituto Nacional de Ciencias Médicas y Nutrición «Salvador Zubirán».
}

\begin{tabular}{ll}
\hline & Recomendaciones, nomenclatura y descripción \\
\multicolumn{1}{c}{ Término } & \multicolumn{1}{c}{ Definición } \\
\hline Obligatorio & Se debe incorporar en todos los casos \\
Sugerido & Se invita a ser incorporado en la mayoría de los casos \\
Deseable & Se considera necesario, pero no es una prioridad \\
\hline
\end{tabular}

1 Toda pareja de receptor y su donante deben tener documentado el grupo sanguíneo (obligatorio).

1A.En caso del grupo sanguíneo $A$, se deberá tener el subtipo de $A(A 1 \circ A 2)$ (obligatorio).

2. El donante y su receptor a trasplantar deberá contar con tipificación HLA completa, que incluye los locus HLA-A, -B, -C, -DR, -DQ y -DP (sugerido). Es conocida la poca accesibilidad a laboratorios de trasplantes tanto por la falta de disponibilidad en el centro de trasplantes como por las limitaciones de costo para realizarlos en otro laboratorio. En este sentido, se exhorta a los diferentes centros de trasplantes para que en el corto o mediano plazo hagan las gestiones para contar con dichos estudios y poder cumplir con este punto. Se espera que en el mediano plazo esto sea obligatorio.

3. A todo receptor se le deberá medir anticuerpos anti-HLA (sugerido). De manera semejante al punto anterior, se espera que en el mediano plazo esto sea obligatorio.

4. Se deberá realizar al menos un tipo de prueba cruzada, de las referidas enseguida, a todo receptor con su donante (obligatorio).
5. Deberá establecerse en el expediente el riesgo inmunológico de cada receptor de trasplante de órgano sólido (obligatorio).

\section{SUSTENTO DE LAS RECOMENDACIONES}

Tipos de rechazo agudo

Desde el inicio de los trasplantes experimentales en animales era evidente que un aloinjerto disfuncionaba rápidamente si no se daba inmunosupresión (inexistente al inicio). Al examinar al microscopio muestras de esos aloinjertos era evidente una gran infiltración por linfocitos, y por otro lado, in vitro, al exponer suero del potencial receptor a linfocitos del potencial donante se observaban reacciones de isoaglutinación, lo que hablaba de la presencia de citotoxinas. De ahí que desde el inicio había dos teorías para explicar un rechazo del injerto: la teoría celular y la teoría humoral. Dado que lo único que se podía demostrar era los infiltrados celulares en las biopsias, la teoría celular predominó por más de 40 años, hasta que se logró demostrar la fijación de complemento en los tejidos (C4d), lo que sólo podía darse por su unión a los anticuerpos. En la actualidad, sabemos que existen rechazos celulares, humorales y mixtos, el daño mediado por anticuerpos es la principal causa de pérdida del injerto. ${ }^{1}$

Desde el punto de vista histológico, los rechazos agudos se estratifican por gravedad de acuerdo con la clasificación de Banff que se revisa cada dos años y se actualiza cuando así se requiere. La vigente hasta el momento es Banff 2017 (revisar referencia para mayor 
información). ${ }^{2}$ Ésta divide a los rechazos en celulares, humorales o mixtos. La categoría más baja de rechazo agudo celular es $1 \mathrm{~A}$, seguida de $1 \mathrm{~B}, 2 \mathrm{~A}, 2 \mathrm{~B}$ y 3 ; la primera se trata con bolos de metilprednisolona y el resto, además de ésta, requiere uso de timoglobulina. Por otro lado, los rechazos humorales requieren para su diagnóstico: 1) hallazgos histopatológicos sugerentes, 2) demostrar anticuerpos anti-HLA donador específico en suero y 3) evidencia del daño endotelial por anticuerpos con la presencia de C4d en tejido o que la suma de glomerulitis $(\mathrm{G})+$ capilaritis peritubular (PTC) sea $\geq 2$. Estos requieren acciones combinadas con terapias para remover o inactivar los anticuerpos circulantes como plasmaféresis, inmunoglobulina intravenosa o enzimas que degradan IgG como imlifidasa, destrucción de linfocitos B CD20+ con rituximab u obinutuzumab, destrucción de células plasmáticas mediante inhibidores del proteasoma como bortezomib y carfilzomib o uso de anticuerpos anti-CD38 como daratumumab, bloqueo de la cascada de complemento mediante eculizumab o inhibidores de $\mathrm{C} 1$, así como otras terapias en desarrollo que inhiben diferentes citocinas como IL6 o BTK. Ante la falta de evidencia sólida de gran parte de esas terapias, hasta hoy el estándar de tratamiento del rechazo humoral es ajustar la inmunosupresión de base, bolos de metilprednisolona, plasmaféresis, inmunoglobulina intravenosa y rituximab. ${ }^{3}$

\section{PRUEBAS DE LABORATORIO PARA LA EVALUACIÓN INMUNOLÓGICA}

Para reducir el riesgo de rechazo agudo debemos realizar algunos estudios de laboratorio muy especializados que nos permitan establecer el riesgo inmunológico de un receptor para un donante específico. Para esto, establecemos el grado de compatibilidad del grupo ABO y la compatibilidad de los antígenos HLA, además de evaluar la presencia en el receptor de anticuerpos preformados contra los antígenos leucocitarios humanos (HLA) del donador, debidos a trasplantes previos, embarazos y transfusiones sanguíneas. ${ }^{4}$ Los estudios que se deben realizar tienen que incluir al menos:

- Grupo sanguíneo: en trasplante renal de donante vivo se deben respetar las leyes de la transfusión sanguínea. Es importante saber que el grupo $A$ tiene subtipo 1 y 2 , el grupo A2 se maneja como grupo $O$ (puede donar a cualquier grupo), mientras que el grupo A1 no le puede donar al A2. En donante fallecido las listas de espera son independientes para cada grupo sanguíneo: $A, B, A B$ y $O$.
Hay excepciones en las que se pueden hacer trasplantes de donante vivo $A B O$ incompatible, pero escapan de los fines de este documento y, para ello, cada centro deberá tener los entrenamientos correspondientes y herramientas necesarias antes de realizarlos. ${ }^{4}$

- Tipificación HLA: hoy en día se pueden tipificar el HLA-A, -B, -C, -DR, -DQ y -DP, pero varía de laboratorio a laboratorio, principalmente por costos, entendiendo que mientras más completo es más útil pero más costoso. Si bien existe la técnica por serología (baja resolución), en la actualidad se deben utilizar técnicas basadas en ADN (mediana resolución). Estos antígenos son muy polimórficos, de tal manera que se han identificado múltiples alelos y siguen incrementándose con el paso del tiempo. Cuando los donadores son padres o hijos, siempre compartirán un haplotipo; pese a ello, es relevante tipificarlo para saber si los anticuerpos detectados son "donador específico». Si dona un hermano(a) hay $25 \%$ de probabilidad que compartan dos haplotipos, $50 \%$ que compartan un haplotipo y $25 \%$ que compartan 0 haplotipos. Cuando comparten dos haplotipos, el riesgo inmunológico es muy bajo y el pronóstico es infinitamente mejor; por ello, siempre habrá que tipificar primero a todos los hermanos dispuestos a donar, aunque otro familiar quiera estar como primera opción, para seleccionar el mejor candidato en todos los aspectos. El costo de hacer más tipificaciones se compensa con la reducción en gastos de la terapia de inducción e inmunosupresión, además de un mejor pronóstico. ${ }^{4}$

- Determinación de anticuerpos anti-HLA: cuantificación de anticuerpos anti-HLA preexistentes en el suero del receptor. Se recomienda que se hagan con tecnología Luminex. Hay tres tipos de reactivo o pruebas con Luminex: 1) como escrutinio (cada esfera contiene 18 antígenos HLA diferentes), el resultado es positivo o negativo; es poco útil en realidad y varios anticuerpos detectados por single antigen no se pueden detectar con esta técnica; 2) porcentaje de panel de anticuerpos reactivos -\%PRA- (cada esfera contiene seis antígenos HLA clase I o seis antígenos HLA clase II) que se expresa como porcentaje y refleja el porcentaje de los posibles donantes que serían incompatibles con el receptor, sólo útil para listas de espera de donante fallecido; 3) anticuerpos específicos (cada esfera tiene sólo un antígeno HLA -single antigen-): determina específicamente contra cuál antígeno HLA 
están dirigidos los anticuerpos preexistentes en el receptor y se puede conocer si están dirigidos contra el donante (una vez tipificado). Es una prueba altamente sensible y específica, recomendable para pretrasplante y para seguimiento. Con este estudio y utilizando las diferentes calculadoras disponibles online se puede calcular el \%PRA. ${ }^{4}$

- Pruebas cruzadas: se utilizan para evaluar la compatibilidad entre donante y receptor. Existen tres métodos principales que en orden de menor a mayor sensibilidad serían: 1) citotoxicidad dependiente del complemento (CDC), en el que una prueba cruzada positiva es una contraindicación absoluta para el trasplante e incluso no son candidatos a protocolos de desensibilización. Es muy operador dependiente y por ello está cayendo en desuso en la mayoría de los laboratorios de trasplante alrededor del mundo. 2) La citometría de flujo es más sensible que la prueba cruzada de CDC. Una citometría de flujo positiva y prueba cruzada mediante CDC negativa no contraindica el trasplante, pero se sugiere hacer desensibilización y con seguimiento postrasplante estrecho.
3) La prueba cruzada virtual con Luminex es más sensible que las dos previas; se requiere conocer los anticuerpos anti-HLA donante específico presentes en el receptor y para ello deben estar tipificados donante y receptor. Una prueba cruzada virtual positiva con las otras dos negativas no contraindica el trasplante, pero se sugiere inducción con timoglobulina e inmunosupresión potente, con vigilancia estrecha postrasplante. 4) Finalmente, una nueva prueba llamada FlowDSA-XM ya está siendo utilizada en México por algunos laboratorios (a pesar de que sólo está autorizada en USA para fines de investigación y no para uso diagnóstico, debido a que no ha sido validada, tal como lo señala la propia página web del fabricante). Esta prueba es una mezcla de citometría de flujo tradicional con Luminex, dado que utiliza perlas de Luminex, pero en lugar de tener antígenos HLA en la superficie, tiene anticuerpos anti-HLA clase I y clase II. Estas perlas se ponen a incubar con un lisado de células sanguíneas que exponen los antígenos HLA y así se unen a los anticuerpos de las perlas. Una vez que se tiene este comple-

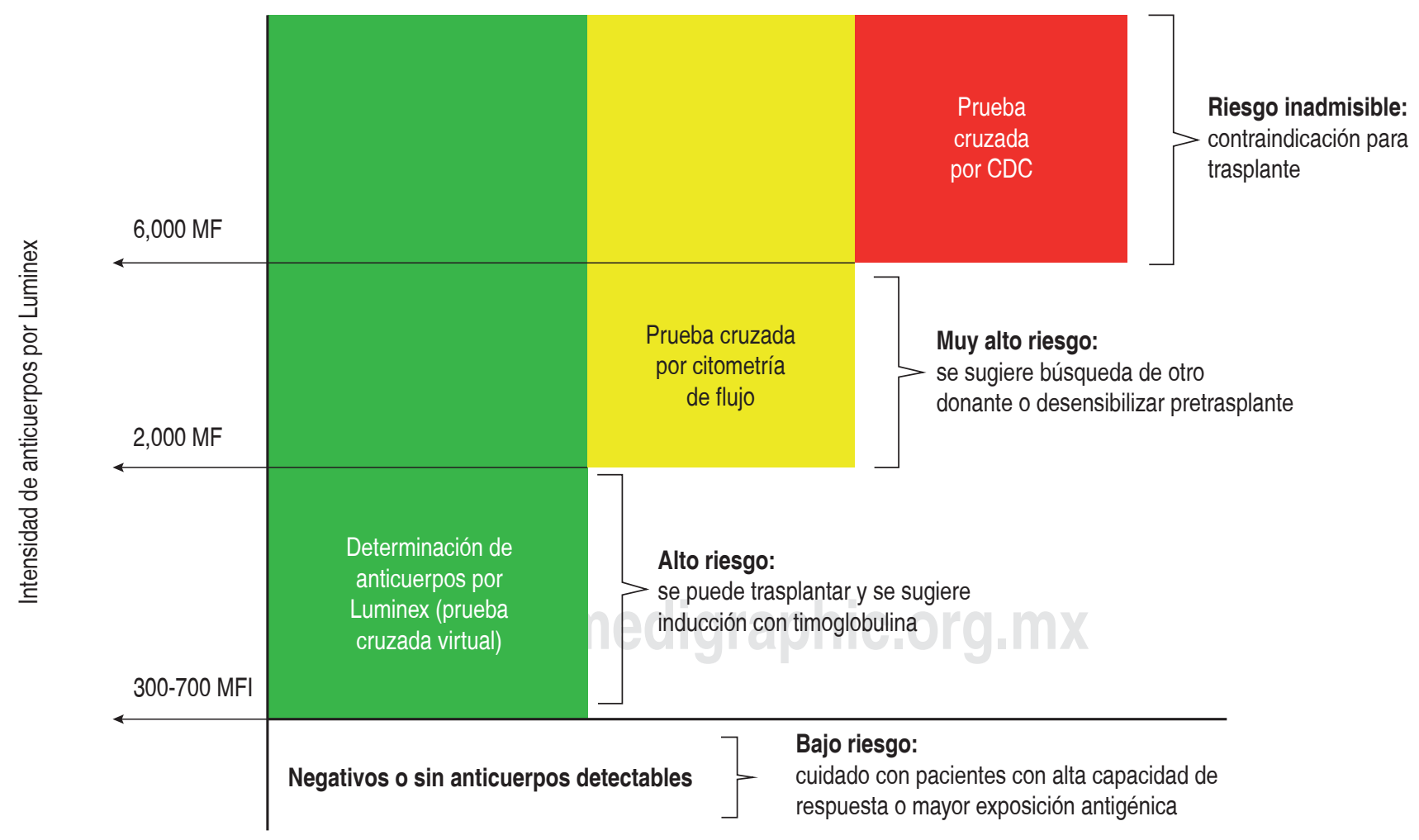

Figura 1: Estratificación del riesgo inmunológico basados en los resultados de las diferentes técnicas de pruebas cruzadas. 
jo se hace el resto del procedimiento semejante a una citometría de flujo, leyendo las perlas por un citómetro de flujo tradicional. El reporte se da como POSITIVO/NEGATIVO para clase I y clase II, haciendo referencia al tipo de anticuerpo antiHLA de las perlas. Si bien, se ve prometedor, no ha demostrado ser superior a las otras técnicas y con frecuencia hay resultados que no concuerdan cuando se compara con lo observado con CDC + Luminex, además de ser muy costoso. El costo aproximado de la prueba FlowDSA-XM es casi la suma del costo de citometría tradicional más single antigen por Luminex, sin duda, en lo personal sugiero con mucho, esta última combinación. ${ }^{4}$

Las opciones para pacientes con incompatibilidad HLA o ABO, pero que cuentan con donantes aceptables desde el punto de vista médico, incluyen programas de desensibilización, trasplante con incompatibilidad $A B O$ y programas de intercambio de donadores tanto a nivel local, nacional o internacional, según en el centro en que se realiza.

\section{ESTRATIFICACIÓN DEL RIESGO INMUNOLÓGICO}

Para establecer el riesgo inmunológico se toman en cuenta características del paciente que lo hacen más proclive a tener gran cantidad de anticuerpos, tales como pacientes previamente sensibilizados (historia de trasplantes, transfusiones o embarazos); pacientes con un sistema inmunológico más agresivo o con mayor capacidad de respuesta como aquéllos de raza negra, niños y jóvenes; pacientes con $\mathrm{VIH}$ o con lupus eritematoso sistémico; aquéllos con mayor riesgo de generar anticuerpos al aumentar la exposición antigénica, como aquél de trasplante de donante fallecido, tiempos de isquemia prolongados, pobre compatibilidad HLA y finalmente, el riesgo establecido con las pruebas inmunológicas al mostrar la presencia de anticuerpos y más aún si están dirigidos a los antígenos del donante. ${ }^{5}$

De todos los factores considerados clasificatorios de alto riesgo inmunológico, los más importantes son aquéllos que dependen de los estudios inmunológicos que se realizan en el laboratorio de histocompatibilidad, dado que ya existe la demostración de anticuerpos (cuando aplica) y no sólo el riesgo de generarlos. Como se explica previamente, se recomienda utilizar la técnica Luminex con single antigen para medir los anticuerpos pretrasplante. Al combinar el resultado de esta prueba con los resul- tados de pruebas cruzadas por los otros métodos podemos estratificar el riesgo inmunológico como se muestra en la Figura $1 .^{5}$

Si existen anticuerpos dirigidos contra el donante (prueba cruzada virtual positiva) con una prueba de citotoxicidad dependiente del complemento (CDC) positiva, se habla de una cantidad muy alta de anticuerpos que confiere un riesgo inadmisible para el receptor de hacer un rechazo hiperagudo postrasplante, de tal manera que está contraindicado el trasplante y en esta situación ningún centro alrededor del mundo opta por desensibilizarlo ante la baja tasa de éxito. Por otro lado, una prueba cruzada virtual positiva, con prueba cruzada por citometría de flujo (CF) positiva y CDC negativa, le confiere muy alto riesgo de rechazo mediado por anticuerpos postrasplante, por lo que se sugiere buscar otro donante y si esto no es posible, se sugiere desensibilizar pretrasplante. En casos donde sólo la prueba cruzada virtual es positiva, si se considera de alto riesgo, dado que tiene anticuerpos dirigidos contra el donante, pero se pudiera trasplantar utilizando timoglobulina y un esquema de inmunosupresión de mantenimiento adecuado con vigilancia estrecha postrasplante. ${ }^{5}$

El tener anticuerpos no específicos en gran cantidad puede hablar de una gran capacidad de respuesta inmunológica y habría que vigilar estrechamente e incluso utilizar una inducción más potente (mediano riesgo). Por último, aquéllos sin anticuerpos medibles podrían considerarse de mediano-bajo riesgo, pero como se mencionó previamente deberá tomarse en cuenta las características del receptor y el riesgo de aumentar la exposición antigénica, dado que muchos de estos pacientes nunca han sido expuestos a factores sensibilizantes; sin embargo, eso no garantiza que no respondan agresivamente ante la presencia del injerto. Para fines prácticos, el único considerado de bajo riesgo es el receptor que comparte dos haplotipos con su donante. ${ }^{5}$

\section{REFERENCIAS}

1. Sellarés $J$, de Freitas DG, Mengel $M$ et al. Understanding the causes of kidney transplant failure: the dominant role of antibodymediated rejection and nonadherence. Am J Transplant. 2012; 12 (2): 388-399.

2. Haas M, Loupy A, Lefaucheur $\mathrm{C}$ et al. The Banff 2017 kidney meeting report: revised diagnostic criteria for chronic active $\mathrm{T}$ cell-mediated rejection, antibody-mediated rejection, and prospects for integrative endpoints for next-generation clinical trials. Am J Transplant. 2018; 18 (2): 293-307.

3. Jordan SC, Ammerman N, Choi $\mathrm{J}$ et al. Novel Therapeutic approaches to allosensitization and antibody-mediated rejection. Transplantation. 2019; 103 (2): 262-272. 
4. Morales-Buenrostro LE. Estudios inmunológicos en el receptor de trasplante renal. En: Morales-Buenrostro LE. Evaluación del riesgo inmunológico y terapia de inducción en trasplante renal. México: Graphimedic S.A. de C.V.; 2016. pp. 11-33.

5. Morales-Buenrostro LE. Estratificación del riesgo inmunológico previo al trasplante. Criterios y evidencia científica. En: MoralesBuenrostro LE. Evaluación del riesgo inmunológico y terapia de inducción en trasplante renal. México: Graphimedic S.A. de C.V.; 2016. pp. 34-42.

\author{
Correspondencia: \\ Dr. Luis Eduardo Morales-Buenrostro \\ E-mail: luis_buenrostro@yahoo.com
}

